\title{
An improved Malaysian automatic license plate recognition (M-ALPR) system using hybrid fuzzy in $\mathrm{C}++$ environment
}

\begin{abstract}
In this paper, an improved hybrid fuzzy technique (Fuzzy Logic and Template matching) for Malaysian Automatic License Plate Recognition (M-ALPR) system is proposed. The system is proposed to reduce the program complexity of the existing M-ALPR system and to decrease the processing time of recognizing Malaysian license plates. First, the algorithm to recognize the license plates is presented, by taking advantage of Matlab and $\mathrm{C}++$ programming language benefits in order to increase system efficiency. Feature extraction using vertical line counter is introduced in this system. Later, with the help of OpenCV, the hybrid fuzzy technique is developed using the $\mathrm{C}++$ language. Then, the comparison between these two implementations on M-ALPR system was reported. The improved system was tested on 740 samples images from real scene and the results show that the proposed improvement supports the accurateness and high speed processing of M-ALPR system.
\end{abstract}

